\title{
FERRAMENTA DIAGNÓSTICA NA GESTÃO INTEGRADA DE ALMOXARIFADOS: UMA PROPOSTA À LUZ DA SUSTENTABILIDADE
}

\author{
Ruth Soares Costa (IFRN) ruthsoares125@gmail.com \\ Ariadny de Sousa Pereira (IFRN) ariadnydesousa@gmail.com \\ Adriane Araújo da Fonseca (IFRN) adrianefonseca2001@ gmail.com \\ Manuely Alves Dantas de Caldas (IFRN) manuelyalves12345@gmail.com
}

\section{Resumo}

A proteção do meio ambiente tem sido bastante discutida por governos, empresas e sociedade civil em virtude dos graves impactos ambientais causados pela ação humana e a má gestão dos recursos naturais. Logo, torna-se necessário encontrar práticas, que englobe o meio social, ambiental e econômico, a fim de não comprometer as atuais e as futuras gerações. Dessa forma, a presente pesquisa tem como finalidade verificar o potencial sustentável da proposta de integrar a gestão dos almoxarifados na rede de Institutos Federais do Rio Grande do Norte, através de uma nova metodologia diagnóstica à luz de 3 dimensões da sustentabilidade ambiental, econômica e social. O trabalho tem como característica um estudo aplicado e possui caráter descritivo e exploratório, visto que há pouca visibilidade da temática no meio acadêmico acerca do setor público. Como resultado, apresentou-se na metodologia uma mensuração baseada em três níveis, nos quais foram utilizados para saber se as ações auxiliam na melhoria ou na efetuação de uma prática sustentável.

Palavras-Chaves: Sustentabilidade; Avaliação da sustentabilidade; Almoxarifado;

\section{Introdução}

A partir do final do século XX, é notória a crescente preocupação da sociedade com os impactos ambientais e sociais, uma vez que tem se demonstrado um aumento de problemas manifestados a partir do desequilíbrio ambiental. Segundo o Programa das Nações Unidas para o Meio Ambiente (2016), a principal causa de morte por degradação ambiental é a poluição do ar, responsável por 7 milhões de falecimentos por ano. Desse modo, torna-se necessário encontrar medidas, na qual englobe o meio social, ambiental e econômico, a fim de não comprometer as futuras gerações. 
Por outro lado, no âmbito econômico, empresas buscam alternativas viáveis para contornar custos sem prejudicar a produtividade. As práticas ambientais imersas nas estratégias organizacionais abarcam como uma oportunidade de redução desses custos, já que uma organização poluente é, geralmente, também uma entidade que desperdiça matéria-prima, insumos e energia (DORIAN et al., 2011). Henri e Journeault (2007) destacam que as práticas de uma gestão ambiental são de suma importância, pois auxiliam a tomada de decisões e a melhoria do desempenho. Diante tal contexto, as práticas sustentáveis têm sido adotadas em repartições privadas e públicas para um desenvolvimento sustentável.

Desenvolvimento sustentável é aquele que atende as necessidades das gerações atuais em comprometer a capacidade das gerações futuras de atenderem às suas necessidades e aspirações (BRUNDTLAND, 1987). As práticas ambientais podem gerar vantagem competitiva utilizando-se de estratégias de baixo custo. Uma melhor gestão dos recursos naturais e minimização de desperdício no processo produtivo representam uma redução nos custos e, consequentemente, podem levar uma empresa a alcançar um diferencial competitivo frente as suas concorrentes (PORTER; VAN DERLINDE, 1995).

Diante o panorama apresentado, o aprimoramento da globalização e suas tecnologias podem promover meios sustentáveis com a utilização de ferramentas, como é o caso dos sistemas de informações. Por abranger pessoas, máquinas e métodos, permitem o apoio à tomada de decisão que auxiliam na elaboração de estratégias aliando à sustentabilidade à possibilidade de ganhos. Segundo Christopher (2000), as informações compartilhadas entre os parceiros da cadeia de suprimentos só podem ser plenamente aproveitadas se houver a integração de processos empresariais. Faz-se necessário que se tenha um trabalho de cooperação de modo que esses processos possam integrar-se de forma sustentável e competitiva, formando, portanto, uma rede interdependente.

O presente artigo tem como objetivo verificar o potencial sustentável da proposta de integrar a gestão dos almoxarifados na rede de Institutos Federais do Rio Grande do Norte, através de uma nova metodologia diagnóstica à luz de 3 dimensões da sustentabilidade - ambiental, econômica e social. Ademais, este estudo se justifica devido à importância da temática do desenvolvimento sustentável e seus reflexos no setor público.

\section{Referencial teórico}




\subsection{Sustentabilidade}

Powlowski (2008) afirma que a sustentabilidade é formada pelas dimensões política, social, moral, econômica, legal, técnica e ambiental. Por outro lado, segundo Munasinghe (2007), para que um desenvolvimento seja considerado sustentável necessita uma análise balanceada e integrada a partir das perspectivas econômica, social e ambiental. Ademais, Munasinghe (2007) complementa que a dimensão ambiental da sustentabilidade se centra no normal funcionamento dos sistemas naturais e preocupa-se com a saúde dos sistemas vivos através da conservação do vigor, resiliência e organização destes.

Biderman (2008) descreve que a noção de sustentabilidade é baseada no imperativo garantia de disponibilidade dos recursos para nossos descendentes, através de uma gestão que contemple a proteção ambiental, a justiça social e o desenvolvimento sadio da economia em nossas sociedades.

Alves et al. (2017) explicita que é notória a importância de uma abordagem ambiental dinâmica e complexa para evitar uma inflexão muito forte e irreversível no processo produtivo em virtude do agravamento dos problemas ambientais, o que provocaria consequências muito graves no âmbito sócio-econômico-ambiental. Não há hierarquia ou prevalência entre variáveis, por isso é imprescindível considerá-las conjuntamente.

Quatro focos principais devem ser considerados para o estabelecimento de políticas econômicas ambientalmente sustentáveis, conforme descreve Alves et al. (2017): a insubstituibilidade dos recursos naturais e dos serviços ecossistêmicos; a incerteza quando se trata de questão ambiental; a irreversibilidade de muitas ações humanas sobre o meio ambiente; e a busca pela equidade inter e intrageracional.

\subsubsection{Sustentabilidade nas organizações}

A organização sustentável seria aquela que consegue, efetivamente, gerar lucro para proprietários e acionistas, protege o meio ambiente e melhora a vida das pessoas com as quais mantém interações (LÉON-SORIANO, MUNÕZ-TORRES e CHALMETA-ROSALEN, 2010).

Os três aspectos da sustentabilidade organizacional (social, ambiental e econômica) devem ser trabalhados de forma conjunta, objetivando o alcance de uma instância maior e mais complexa, 
que é o desenvolvimento sustentável (CALLADO, 2010). No ponto de vista de Dias (2015), o desenvolvimento sustentável está associado ao termo sustentável e relacionado às diversas interações, dentre elas, entre os sistemas sociais, econômicos e ambientais. Anninos e Chytiris (2012) acrescentam que, nas organizações, a visualização da necessidade de desenvolvimento simultâneo da economia, da sociedade e do meio ambiente, denomina-se gestão sustentável.

\subsubsection{Avaliação da Sustentabilidade}

Conforme Assunção (2018) ainda não há um consenso universal sobre o que é a avaliação da sustentabilidade, tampouco como ela deve ser empregada. Há diversas ferramentas e técnicas que podem apoiar processos de avaliação, particularmente em termos de integração que refletem os três pilares do desenvolvimento sustentável.

A avaliação da sustentabilidade pode ser incrementada por estudos de desempenho. Consoante a isso, Assunção (2018) complementa que o objetivo central do estudo do desempenho é a mensuração dos resultados da transformação de entradas em produtos associados às questões do meio ambiente, sejam indesejáveis ou desejáveis.

Rocha et al. (2020), referenciando Sachs (1993), alega que a sustentabilidade, na dimensão ambiental, ou ecológica, é avaliada por meio de ações, dentre as quais se destacam: Uso dos recursos naturais com um menor dano possível aos diversos ecossistemas; Redução da geração de resíduos sólidos e de poluição, bem como uso de alternativas que minimizem os impactos negativos no meio ambiente; Definição de regras e procedimentos voltados para proteção ambiental e estabelecimento de requisitos legais, administrativos e outros que assegurem o cumprimento das regras definidas.

Segundo Van Bellen (2005) a complexidade dos problemas do desenvolvimento sustentável requer a agregação de diferentes indicadores formando, assim, um sistema. Nesse sentido, Quiroga (2005) aponta que os indicadores ambientais, os sociais e os econômicos podem ser confrontados em uma base comum de informações.

\subsection{Compras públicas}

Aliada aos critérios de eficiência, a Administração Pública se rodeia de outros pilares indissociáveis de sua natureza, como dar publicidade de seus atos, tratamento isonômicos aos cidadãos, dentre outros (PALUDO, 2013). 
No setor público, as compras necessitam de vários requisitos legais, o que as tornam bastante complexas. Por isso, os órgãos públicos, em suas compras necessitam realizar processos denominados de licitações. As obras, serviços, compras, alienações, concessões, permissões e locações, quando contratadas com terceiros, serão necessariamente precedidas de licitação.

Paludo (2013) explica que além do dever de realizar licitações, a Administração Pública tem outras prerrogativas, como dar publicidade aos atos praticados, tratamento isonômico e ser justa, dando tratamento igualitário a todas as empresas que estiverem aptas a lhe fornecer produtos, materiais e serviços.

\subsubsection{Compras públicas sustentáveis}

A gestão ambiental no setor público, segundo Barbieri (2007) compreende a atuação do poder público, conduzida segundo uma política pública ambiental por meio de objetivos, diretrizes e instrumentos de ação, no sentido de obter resultados positivos ao meio ambiente. A sustentabilidade econômica, social e ambiental é um dos grandes desafios da humanidade e exige ação do poder público para que seja possível garantir a inserção da variável socioambiental no processo decisório, particularmente na formulação das políticas públicas (A3P, 2009).

Sachs (2009) argumenta se tratando de desenvolvimento, partindo do princípio da sustentabilidade, é de extrema importância à necessidade de um Estado atuante. Estudos mostram que a utilização de produtos, serviços e obras de menor impacto ambiental reduzem os gastos do governo com políticas de reparação de danos ambientais (VOGELMANN JR, 2014). Coelho (2014) defende que o poder público tem o dever de liderar o aguçamento da consciência ambiental, por meio de suas vultosas aquisições, capazes de incentivar indústria, comércio e consumidores a utilizar bens e serviços ambientalmente corretos.

Segundo Oliveira e Santos (2015), o conceito de compras sustentáveis busca incorporar simultaneamente critérios de eficiência econômica, social e ambiental que busca entender a realidade numa amplitude de contornos, o que tende a gerar resultados que superam as fronteiras tradicionais de cada política pública. Biderman (2008) reforça que as compras sustentáveis não podem permitir gastos adicionais significativos.

As compras públicas sustentáveis são ferramentas que permitem aos governos alavancarem os gastos públicos, a fim de promoverem políticas sociais, ambientais e econômicas do país, além 
de contribuir para a criação de mercados para tecnologias apropriadas e soluções inovadoras (UNEP, 2014).

Gunther e Scheibe (2006) argumentam que existem empecilhos para a relização de compras públicas sustentáveis. As principais dificuldades destacadas para a realização de Compras Públicas Sustentáveis são: a possibilidade de esta não ser um objetivo da organização, a falta de incentivos, a falta de conhecimento e informação e a falta de regulamentação.

\subsection{Gestão de Almoxarifado}

Segundo com Fenili (2015), almoxarifados são locais destinados à guarda e à conservação dos itens de material em estoque de uma determinada organização, é essencial que a gestão dos almoxarifados seja eficiente, visando minimizar os custos de armazenamento de estoques bem como maximizando a qualidade de atendimento aos seus clientes internos à empresa.

\subsection{Sistemas de informação na gestão de almoxarifado}

Segundo O'brien (2013), o papel estratégico dos sistemas de informação envolve a utilização de tecnologias de informação para desenvolver produtos, serviços e capacidades que configuram a uma empresa vantagens estratégicas sobre as forças competitivas que ela enfrenta no mercado global.

Consoante a Viana (2010), os benefícios gerados pela informatização desenvolverem e oferecerem uma série de softwares de gerenciamento de estoques, plenamente exequíveis e adaptáveis às empresas de pequeno e médio porte.

\section{Metodologia}

Este artigo trata-se de uma pesquisa de natureza aplicada, pois objetiva gerar conhecimentos para aplicação prática (SILVEIRA; CÓRDOVA, 2009), relevante ao setor público. Além disso, a pesquisa apresenta caráter exploratório e descritivo, devido ao desprovimento de informações específicas sobre o tema estudado. Conforme aponta Vieira (2010), a composição exploratória permitiu torná-la mais explícita, além de utilizar técnicas padronizadas de coleta de dados de acordo a sua característica descritiva. 
Ao que se refere em sua abordagem, à pesquisa é caracterizada como qualitativa, pois discute aspectos sociais, econômicos, ambientais das operações na gestão pública dos recursos, extraídos a partir do Instituto Federal do Rio Grande do Norte, campus São Gonçalo do Amarante. Nos procedimentos técnicos, o presente estudo constitui-se de levantamentos bibliográficos sobre a temática.

Os procedimentos da presente pesquisa se dividem em 4 partes. Primeiramente, realizou-se o levantamento bibliográfico, no qual se obteve uma base teórica. Foram efetuadas pesquisas na literatura e em produções acadêmicas existentes acerca dos tópicos: Sustentabilidade, Gestão de almoxarifado e Compras públicas.

Em segundo plano, executou-se uma coleta de dados na instituição de ensino federal. Como instrumento principal para o levantamento de informação, foi investigada as operações do Instituto Federal do Rio Grande do Norte, campus São Gonçalo do Amarante, afim de identificar gargalos e desperdícios no campus. Como forma de atender o objetivo, os resultados construídos estão baseados na realização de técnicas de observação e descrição dos locais, bem como entrevistas com os gestores da instituição.

Em seguida, passou-se à criação de perguntas que formam os critérios da ferramenta. Como resultado, a pesquisa expôs um diagnóstico, e o grau, da proposta com base nos 29 critérios avaliados frente aos aspectos ambientais, sociais e ambientais. $\mathrm{O}$ estudo das ações institucionais que a instituição realiza serviu para a contextualização dos resultados, dentro de uma abordagem atual e coerente.

Logo após, sucedeu-se o tratamento dos dados. Foram abstraídos os detalhes de dados descritivos para visualizar a aplicação sustentável no IFRN. Para apresentar esses aspectos, realizaram-se projeções em gráficos à atuação da integração da gestão dos almoxarifados. Por fim, apresentou-se uma conciliação com embasamento teórico.

\section{Resultados}

O almoxarifado do Instituto Federal do Rio Grande do Norte, campus São Gonçalo do Amarante, conta com diversos materiais cadastrados, que se encontram armazenados em cinco unidades distintas dentro do campus, onde trabalham dois servidores na gestão e recebe-se o auxílio de uma empresa terceirizada para a manutenção dos locais. 
São demandas do almoxarifado no seu cotidiano, as atividades de:

a) Armazenagem de material e estruturação de estoque;

b) Recebimento e conferência dos materiais adquiridos e/ou cedidos;

c) Registro no Sistema Unificado de Administração Pública (SUAP) - dos documentos relativos aos materiais recebidos;

d) Distribuição dos materiais recebidos;

e) Emissão e controle de pedidos de compras de materiais solicitados através das demandas setoriais do campus.

Tendo em vista que o IFRN se trata de uma organização pública, toda aquisição necessária é feita a partir de processos licitatórios. Consoante a isso, a ação de aquisição se torna um gargalo relevante do almoxarifado do campus e, também, do setor de finanças, que realiza a função de compra. Apesar das licitações terem o objetivo de minimizar os custos, são morosos e podem levar até 3 meses para concluírem. Tal demora acarreta, consequentemente, na dificuldade de aquisição de materiais, o que impacta o funcionamento da instituição como um todo.

Em relação ao sistema utilizado pelo instituto, o SUAP é trabalhado em uma plataforma individual a cada campus, logo, não há uma interface virtual que unifique os almoxarifados do campus São Gonçalo do Amarante aos demais 20 campi que formam a rede IFRN. Dessa forma, impossibilita que o material que sobra ou que está obsoleto em um campus possa ser solicitado e, portanto, transferido a outro campus. Além disso, é inviabilizado a integração das demandas dos almoxarifados, o que gera aumento dos custos e certo desperdício das compras entre os campi. Ressalva-se que os recursos públicos, tendo em vista sua origem na contribuição da sociedade, devem ser utilizados de maneira eficiente, visando sempre alcançar o maior número possível de beneficiários.

Atendendo a Brundtland (1987), Munasinghe (2007) e Biderman (2008), para otimizar os custos, melhorar a gestão e reduzir desperdícios na rede de Institutos Federais do Rio Grande do Norte, propõe-se a integração das atividades de gestão dos almoxarifados dos campi. Para isso, levou-se em consideração o potencial sustentável da proposta mencionada, visto que apresenta impactos no eixo ambiental, social e econômico. Com a finalidade de cumprir o objetivo, desenvolveu-se uma ferramenta metodológica para mensurar e diagnosticar as dimensões ambiental, social e econômica. 
Uma ampla revisão bibliográfica de conteúdo, referente ao objetivo da pesquisa, e, também, às particularidades do setor público, contribuíram para a seleção das dimensões - ambiental social e econômica - da sustentabilidade. Cada dimensão, por sua vez, contempla critérios inerentes as suas características de análise, sendo representados por: ambiental, com 14 critérios; social, com 11 critérios e econômica, com 4 critérios. A Figura 1 apresenta cada um desses critérios separados em sua respectiva dimensão.

Figura 1 - Metodologia diagnóstica com base em três dimensões da sustentabilidade

\begin{tabular}{|l|l|l|l|}
\hline \multicolumn{1}{|c|}{ DIMENSÃO AMBIENTAL } & Sim & Intermediário & Não \\
\hline Promoção da responsabilidade ambiental em longo prazo & & & \\
\hline Avaliação do risco ambiental do produto/serviço & & & \\
\hline Avaliação do desepenho ambiental das compras institucionais & & & \\
\hline Redução de poluentes e materiais perigosos & & & \\
\hline Reciclagem de materiais utilizados nas operações & & & \\
\hline Redução de disperdícios e aproveitamento de materiais & & & \\
\hline Produtos com focos no reuso e reciclagem & & & \\
\hline Foco na redução de consumo de recursos naturais & & & \\
\hline Foco na redução de consumo de energia & & & \\
\hline Redução na emissão de gases poluentes & & & \\
\hline Redução no consumo de água nos processos & & & \\
\hline Destinação dos resíduos sólidos & & & \\
\hline Critérios ambientais para a seleção de fornecedores & & & \\
\hline Critérios ambientais para a avalição de fornecedores & & & \\
\hline Promoção da responsabilidade social em longo prazo & & & \\
\hline Avaliação do risco social do produto/serviço & & & \\
\hline Avaliação do desepenho social institucional & & & \\
\hline Promoção de projetos sociais em tempo integral & & & \\
\hline Participação de funcionários na instituição & & & \\
\hline
\end{tabular}




\begin{tabular}{|l|l|l|l|}
\hline Respeito a legislação federal vigente & & & \\
\hline Critérios socias para a seleção dos fornecedores & & & \\
\hline critérios socias para a avaliação dos fornecedores & & & \\
\hline Promoção de parcerias com outras organizações localizadas próximas & & & \\
\hline Incentivo ao bem-estar de colaboradores & & & \\
\hline Promoção da ética organizacional Total & & & \\
\hline \multicolumn{1}{|c|}{ DIMENSÃO ECONÔMICA } & & & \\
\hline \multicolumn{1}{|c|}{ Total } & & & \\
\hline Promoção de investimento ético & & & \\
\hline Investimento em tecnologias limapas & & & \\
\hline Retornos sobre capital investido & & & \\
\hline Economia de gastos públicos & & & \\
\hline
\end{tabular}

Fonte: Autores (2020)

Para tanto, apresentam-se escalas dos graus de sustentabilidade para todos os critérios que foram selecionados no trabalho, conforme aponta a Figura 1. Ademais, realizou-se os seguintes parâmetros para mensurá-los: Sim - para ações que auxiliam totalmente na melhoria ou efetuação da dimensão; Intermediário - para ações que auxiliam parcialmente na melhoria ou efetuação da dimensão; e Não - para ações que não auxiliam na melhoria ou efetuação da dimensão.

Devido à ausência de um consenso universal sobre a avaliação da sustentabilidade, tampouco o formato que deve ser empregada, segundo aponta Assunção (2018), os critérios foram selecionados com base nas características dos processos descritos pelos gestores, assim como algumas atividades presentes na instituição que incentivam a prática sustentável, embora que, atualmente, não estejam regulamentadas em seu plano de desenvolvimento institucional. Entre os incentivos identificados durante as visitas, destacam-se o estímulo ao uso de energia limpa e o uso de águas pluviais na manutenção do campus a fim de reduzir o consumo de água nos processos.

Ao passo que os critérios são classificados nos três níveis, no final, é possível extrair a ocorrência em relação a cada dimensão. Desta forma, facilita-se a visão das três dimensões como um todo e possibilita realizar análises de como se comporta a prática sustentável em questão. Considerando a metodologia desenvolvida, aplicou-se a ferramenta para identificar o potencial sustentável da proposta de integrar a gestão dos almoxarifados na rede de IFRN, como demonstra a Figura 2. 
Figura 2: Aplicação da metodologia diagnóstica com base em três dimensões da sustentabilidade

\begin{tabular}{|c|c|c|c|}
\hline DIMENSÃO AMBIENTAL & Sim & Intermediário & Não \\
\hline Promoção da responsabilidade ambiental em longo prazo & & $*$ & \\
\hline Avaliação do risco ambiental do produto/serviço & $*$ & & \\
\hline Avaliação do desepenho ambiental das compras institucionais & $*$ & & \\
\hline Redução de poluentes e materiais perigosos & $*$ & & \\
\hline Reciclagem de materiais utilizados nas operações & & & * \\
\hline Redução de disperdícios e aproveitamento de materiais & * & & \\
\hline Produtos com focos no reuso e reciclagem & & $*$ & \\
\hline Foco na redução de consumo de recursos naturais & $*$ & & \\
\hline Foco na redução de consumo de energia & & $*$ & \\
\hline Redução na emissão de gases poluentes & & $*$ & \\
\hline Redução no consumo de água nos processos & & $*$ & \\
\hline Destinação dos resíduos sólidos & & & $*$ \\
\hline Critérios ambientais para a seleção de fornecedores & $*$ & & \\
\hline Critérios ambientais para a avalição de fornecedores & $*$ & & \\
\hline Total & $50 \%$ & $35,7 \%$ & $14,3 \%$ \\
\hline \multicolumn{4}{|l|}{ DIMENSÃO SOCIAL } \\
\hline Promoção da responsabilidade social em longo prazo & $*$ & & \\
\hline Avaliação do risco social do produto/serviço & $*$ & & \\
\hline Avaliação do desepenho social institucional & * & & \\
\hline Promoção de projetos sociais em tempo integral & & $*$ & \\
\hline Participação de funcionários na instituição & $*$ & & \\
\hline Respeito a legislação federal vigente & $*$ & & \\
\hline Critérios socias para a seleção dos fornecedores & $*$ & & \\
\hline critérios socias para a avaliação dos fornecedores & $*$ & & \\
\hline Promoção de parcerias com outras organizações localizadas próximas & $*$ & & \\
\hline Incentivo ao bem-estar de colaboradores & & $*$ & \\
\hline Promoção da ética organizacional & $*$ & & \\
\hline Total & $81,8 \%$ & $18,2 \%$ & $0 \%$ \\
\hline \multicolumn{4}{|l|}{ DIMENSÃO ECONÔMICA } \\
\hline Promoção de investimento ético & $*$ & & \\
\hline Investimento em tecnologias limapas & & $*$ & \\
\hline Retornos sobre capital investido & $*$ & & \\
\hline Economia de gastos públicos & $*$ & & \\
\hline Total & $75 \%$ & $25 \%$ & $0 \%$ \\
\hline
\end{tabular}

Fonte: Autores (2020)

Ao analisar o diagnóstico da Figura 2, percebe-se que tanto na dimensão social como na dimensão econômica se apresentam importantes pontos que agregam para uma prática sustentável e, portanto, são um grande potencial. Similarmente, na dimensão ambiental se apresentam pontos que acrescentam sustentabilidade à prática, embora que, também, possua pontos que atrapalhem a atuação ambiental.

A dificuldade identificada se dá devido à ausência na garantia da aplicação da logística reversa para os resíduos adquiridos durante o processo de integração. Essa particularidade, em relação 
ao fluxo reverso de resíduos, não promove a anulação da proposta, mas que busca, por meio desse diagnóstico prévio, a elaboração de um planejamento maior durante a inclusão dos processos.

Por fim, abstraíram-se os dados do diagnóstico para a apresentação visual do grau das dimensões da sustentabilidade, conforme mostra a Figura 3. A partir disso, foi possível proporcionar uma fácil visualização e investigar o comportamento do gráfico na distribuição dos 3 eixos, considerando a proposta de integrar a gestão do almoxarifado nos cenários onde auxilia, parcialmente auxilia e não auxilia como prática sustentável.

Figura 3 - Gráficos do grau de sustentabilidade nas dimensões ambiental, social e econômica

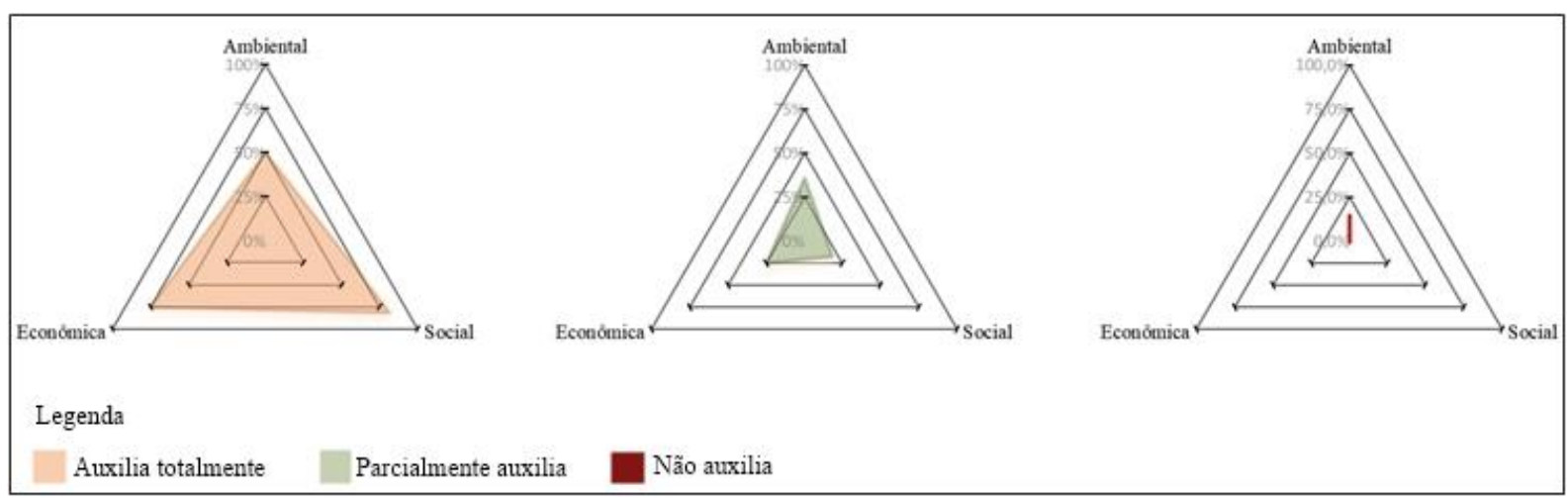

Fonte: Autores (2020)

Os gráficos da Figura 3 permitiram detectar que, de maneira geral, a proposta de integração equilibra-se nas três dimensões auxiliando totalmente em alguns pontos, e parcialmente em outros, para oferecem uma prática mais sustentável à rede IFRN. Em ambos os traços, apresentam-se semelhanças na distribuição do gráfico. Algumas ressalvas são expostas no eixo ambiental que não auxiliam a prática como uma ação sustentável.

\section{Conclusão}

O objetivo deste trabalho foi verificar o potencial sustentável da proposta de integrar a gestão dos almoxarifados na rede de Institutos Federais do Rio Grande do Norte, por meio da utilização de uma nova metodologia diagnóstica à luz de 3 dimensões da sustentabilidade: ambiental, econômica e social. Os resultados apresentados permitiram traçar uma análise de suma relevância para o setor público.

Portanto, é lícito afirmar que a proposta de integrar o gerenciamento dos almoxarifados caracteriza-se como uma prática sustentável, tendo em vista garantia de um retorno à sociedade, ao estímulo dos funcionários e parceiros regionais e à redução do impacto na obtenção de 
matéria-prima. Dessa forma, integrar os almoxarifados da rede IFRN implica em atuar de forma responsável.

Verificaram-se ainda algumas ressalvas na proposta e que, sendo assim, necessitam de um maior planejamento. Uma perspectiva futura necessária para avaliar a proposta é sucessão de um estudo nas diretrizes do Plano de Desenvolvimento Institucional, sob o olhar da sustentabilidade, para a efetuação das práticas sustentáveis.

\section{REFERÊNCIAS}

ALVES, Alessandro Ferreira; JÚNIOR, Pedro dos Santos Portugal; REYDON, Bastiaan Philip. POLÍTICA ECONÔMICA AMBIENTALMENTE SUSTENTÁVEL: por uma adaptação de fundamentos macroeconômicos à sustentabilidade ambiental. Revista Ciências Humanas, v. 10, n. 1-1, p. 72-89, 2017.

ANNINOS, Loukas N.; CHYTIRIS, Leonidas S. The sustainable management vision for excellence: implications for business education. International Journal of Quality and Service Sciences, v. 4, n. 1, p. 61, 2012.

ASSUNÇÃO, M.V.D. O Estudo da eficiência ambiental dos campos onshore das bacias costeiras brasileiras na perspectiva da água produzida de petróleo. (Doutorado em Ciência e Engenharia de Petróleo) - Universidade Federal do Rio Grande do Norte. Natal, 2018.

BARBIERI, José Carlos. Organizações inovadoras sustentáveis: uma reflexão sobre o futuro das organizações. Atlas, 2007.

BIDERMAN, Rachel et al. Guia de compras públicas sustentáveis: uso do poder de compra do governo para a promoção do desenvolvimento sustentável. Centro de Estudos em Sustentabilidade (FGVces), 2008.

BRUNDTLAND, Comissão. Comissão Mundial sobre Meio Ambiente e Desenvolvimento: o nosso futuro comum. Universidade de Oxford. Nova Iorque, 1987.

CALLADO, Aldo Leonardo Cunha. Modelo de mensuração de sustentabilidade empresarial: uma aplicação em vinícolas localizadas na Serra Gaúcha. 2010.

CHRISTOPHER, Martin. The agile supply chain: competing in volatile markets. Industrial marketing management, v. 29, n. 1, p. 37-44, 2000.

COELHO, H. A. Responsabilidade Ambiental na Licitação: Sustentabilidade nas contratações e compras de governo. Rio de Janeiro: Lumen Juris. 2014

DA ADMINISTRAÇÃO PÚBLICA, Agenda Ambiental. A3P. 2009.

DE OLIVEIRA, BCSCM; DOS SANTOS, LML. Compras públicas como política para o desenvolvimento sustentável. Revista de Administração Pública, v. 49, n. 1, 2015. 
DIAS, Reinaldo. Sustentabilidade: origem e fundamentos; educação e governança global; modelo de desenvolvimento. São Paulo: Atlas, p. 210-211, 2015.

DORION, Eric Charles Henri; DE ABREU, Marcelo Faoro; SEVERO, Eliana Andrea. A contribuição da logística reversa e dos sistemas de informação na busca pela sustentabilidade ambiental. Revista de Administração IMED, v. 1, n. 1, p. 97-122, 2011.

FENILI, R.R. Gestão de Materiais. Brasília: ENAP, 2015.

GUNTHER, E.; SCHEIBE, L. The Hurdle Analysis. A Self-evaluation Tool for Municipalities to Identify, Analyse and Overcome Hurdles to Green Procurement. Corporate Social Responsibility and Environmental Management, v. 13, p.61-77, 2006.

HENRI, Jean-Francois; JOURNEAULT, Marc. Environmental performance indicators: An empirical study of Canadian manufacturing firms. Journal of environmental management, v. 87, n. 1, p. 165-176, 2008. International Journal of Business Governance and Ethics, v. 6, n. 1, p. 49-67, 2010.

LEÓN-SORIANO, Raúl; MUÑOZ-TORRES, María Jesús; CHALMETA-ROSALEN, Ricardo. Methodology for sustainability strategic planning and management. Industrial management \&amp; data systems, v. 110, n. 2, p. 249-268, 2010.

MUNASINGHE, Mohan et al. Sustainable development triangle. The Encyclopedia of the Earth, v. 459, 2007.

O’BRIEN, James A.; MARAKAS, George M. Administração de sistemas de informação. AMGH, 2013.

PALUDO, Augustinho. Administração Pública. 3 ed. Rio de Janeiro: Elsevier, 2013.

PAWLOWSKI, Lech. The science and engineering of thermal spray coatings. John Wiley \& Sons, 2008.

PORTER, Michael E.; VAN DER LINDE, Claas. Toward a new conception of the environmentcompetitiveness relationship. Journal of economic perspectives, v. 9, n. 4, p. 97-118, 1995.

PROGRAMA DAS NAÇÕES UNIDAS PARA O MEIO AMBIENTE (PNUMA). Advanced DGEF Database Information System (ADDIS) (2016). Disponível em: 〈http://zip.net/bmtr2w>. Acesso em: 02 de fev 2020.

QUIROGA, Rayén. Estadísticas del medio ambiente en América Latina y el Caribe: Avances y perspectivas. Chile: Cepal, 2005.

ROCHA, Sandra Patrícia Bezerra et al. Indicadores para avaliação multidimensional da sustentabilidade do setor hospitalar que presta serviços públicos. Journal of Environmental Analysis and Progress, v. 5, n. 1, p. 017-030, 2020

SACHS, Ignacy. A terceira margem: em busca do ecodesenvolvimento. Companhia das Letras, 2009. 
SILVEIRA, Denise Tolfo; CÓRDOVA, Fernanda Peixoto. Unidade 2-A pesquisa científica. Métodos de pesquisa, v. 1, 2009.

UNITED NATIONS ENVIRONMENT PROGRAMME. (2014). Sustainable Public Procurement. Disponível em: <http://www.unep.fr/scp/procurement/>;. Recuperado em 2, janeiro, 2020.

VAN BELLEN, Hans Michael. Indicadores de sustentabilidade: uma análise comparativa. FGV editora, 2005.

VIANA, João José. Administração de materiais: um enfoque prático. 13 reimp. São Paulo: Atlas, 2010.

VIEIRA, José Guilherme Silva. Metodologia de pesquisa científica na prática. Curitiba: Editora Fael, 2010.

VOGELMANN JÚNIOR, Jorge Carlos. Roteiro prático de ações públicas. Porto Alegre: ESAF, 2014. 